\title{
Advanced Single-Aisle Transport Propulsion Design Options Revisited
}

\author{
Mark D. Guynn* \\ NASA Langley Research Center, Hampton, VA, 23681 \\ Jeffrey J. Berton ${ }^{\dagger}$, Michael T. Tong ${ }^{\ddagger}$, and William J. Haller ${ }^{\S}$ \\ NASA Glenn Research Center, Cleveland, OH, 44135
}

\begin{abstract}
Future propulsion options for advanced single-aisle transports have been investigated in a number of previous studies by the authors. These studies have examined the system level characteristics of aircraft incorporating ultra-high bypass ratio (UHB) turbofans (direct drive and geared) and open rotor engines. During the course of these prior studies, a number of potential refinements and enhancements to the analysis methodology and assumptions were identified. This paper revisits a previously conducted UHB turbofan fan pressure ratio trade study using updated analysis methodology and assumptions. The changes in propulsion, airframe, and noise modeling are described and discussed. The impacts of these changes are then examined by comparison to the previously reported results. The changes incorporated have decreased the optimum fan pressure ratio for minimum fuel consumption and reduced the engine design trade-offs between minimizing noise and minimizing fuel consumption. Nacelle drag and engine weight are found to be key drivers in determining the optimum fan pressure ratio from a fuel efficiency perspective. The revised noise analysis results in the study aircraft being 2 to 4 EPNdB (cumulative) quieter due to a variety of reasons explained in the paper. With equal core technology assumed, the geared engine architecture is found to be as good as or better than the direct drive architecture for most parameters investigated. However, the engine ultimately selected for a future advanced single-aisle aircraft will depend on factors beyond those considered here.
\end{abstract}

\section{Introduction}

INCE 2006, NASA has been conducting on-going trade studies to assess propulsion options for an advanced single-aisle (Boeing 737/Airbus A320 class) aircraft, initially as part of the Subsonic Fixed Wing (SFW) Project and continuing today in the Fixed Wing Project. The focus of these efforts has been to assess potential technology paths for reaching the NASA "N+1" subsonic transport system level goals shown in Fig. 1. This multi-year, multiphase activity began with an initial concentration on ultra-high bypass ratio (UHB) geared and direct drive turbofan engines. Initial findings, along with multiple interactions with industry partners, were used to refine the UHB analysis process and assumptions over a period of a few years. Then the focus shifted to open rotor (OR) engine options for this class of vehicle. Following a similar path, the initial results were updated and refined based on interaction with industry partners. Numerous technical reports and papers document the results of these studies. ${ }^{1-10}$ Continuous improvement through publication and subsequent discussions and interactions has been a defining characteristic of this multi-year activity. NASA's modeling and analysis tools have also been in a state of continual development over the course of this activity. The analysis processes and "best practices" have evolved over time. Although leading to better study results, such improvements make comparison of recent results to previous findings problematic. Because of the evolving methodologies and modeling assumptions, the Fixed Wing Project recently initiated an effort to update the previous UHB studies, enabling consistent comparisons with the more recent open rotor studies described in Ref. 10.

\footnotetext{
*Aerospace Engineer, Aeronautics Systems Analysis Branch, Mail Stop 442, Senior Member AIAA.

${ }^{\dagger}$ Aerospace Engineer, Multidisciplinary Design, Analysis \& Optimization Branch, MS 5-11, Senior Member AIAA.

*Aerospace Engineer, Multidisciplinary Design, Analysis \& Optimization Branch, MS 5-11.

${ }^{\S}$ Aerospace Engineer, Multidisciplinary Design, Analysis \& Optimization Branch, MS 5-11.
}

1

American Institute of Aeronautics and Astronautics 


\begin{tabular}{|c|c|c|c|}
\hline \multirow{2}{*}{$\begin{array}{c}\text { TECHNOLOGY } \\
\text { BENEFITS* }\end{array}$} & \multicolumn{3}{|c|}{$\begin{array}{c}\text { TECHNOLOGY GENERATIONS } \\
\text { (Technology Readiness Level = 4-6) }\end{array}$} \\
\cline { 2 - 4 } & $\mathrm{N}+1(2015)$ & $\mathrm{N}+2\left(2020^{\star \star}\right)$ & $\mathrm{N}+3(2025)$ \\
\hline $\begin{array}{c}\text { Noise } \\
\text { (cum margin rel. to Stage 4) }\end{array}$ & $-32 \mathrm{~dB}$ & $-42 \mathrm{~dB}$ & $-52 \mathrm{~dB}$ \\
\hline $\begin{array}{c}\text { LTO NOx Emissions } \\
\text { (rel. to CAEP 6) }\end{array}$ & $-60 \%$ & $-75 \%$ & $-80 \%$ \\
\hline $\begin{array}{c}\text { Cruise NOx Emissions } \\
\text { (rel. to 2005 best in class) }\end{array}$ & $-55 \%$ & $-70 \%$ & $-60 \%$ \\
\hline $\begin{array}{c}\text { Aircraft Fuel/Energy Consumption } \\
\text { (rel. to 2005 best in class) }\end{array}$ & $-33 \%$ & $-50 \%$ & -6013.1 \\
\hline
\end{tabular}

* Projected benefits once technologies are matured and implemented by industry. Benefits vary by vehicle size and mission. $\mathrm{N}+1$ and $\mathrm{N}+3$ values are referenced to a 737-800 with CFM56-7B engines, $N+2$ values are referenced to a 777-200 with GE90 engines

** ERA's time-phased approach includes advancing "long-pole" technologies to TRL 6 by 2015

$\ddagger \mathrm{CO} 2$ emission benefits dependent on life-cycle CO2e per MJ for fuel and/or energy source used

Figure 1. NASA subsonic transport system level metrics.

Much has changed in the aircraft industry since 2006 as well. At that time, the expectation was that completely new 737 and A320 replacement aircraft would be available in the mid-2010s. ${ }^{11}$ There are two completely new vehicles in this size class on the horizon, the Comac C919 and the Irkut MC-21, from China and Russia respectively. However, the major western manufacturers, Boeing and Airbus, have chosen to instead re-engine their existing 737 and A320 models, with entry-into-service of the A320neo projected in 2015 and the 737 MAX in 2017. Although the expected all-new Airbus and Boeing aircraft have not emerged, new engines are being developed. When the NASA UHB initial feasibility study was started in 2006, the Pratt \& Whitney PW1000G and CFM International LEAP products were not yet in development. The potential competition between an advanced geared turbofan engine and an advanced direct drive turbofan engine was theoretical. With the geared PW1100G and direct drive CFM LEAP-1A engines both offered on the A320neo, that competition now exists in the single-aisle engine market. Even though the entry-into-service dates for these new engines match the technology dates of the original NASA study, the NASA technology assumptions were aggressive and still represent some advancement beyond the current LEAP and PW1000G engines. This level of technology, referred to as N+1 in NASA terminology, is 5-10 years beyond the new P\&W and CFM engines. This is an important distinction since it has not been, nor is it now, the authors' intent to compare or assess engines that are available in today's market. Rather, the focus is on propulsion choices that will need to be made in the future.

\section{Study Objectives and Approach}

The objective of this study is to revisit previous analyses to assess advanced geared and direct drive turbofans using updated and refined analysis processes and assumptions. The impacts of these changes on prior study conclusions are evaluated. Ultimately, the objective is to enable comparison of the fuel burn, noise, and emissions of geared turbofan, direct drive turbofan, and open rotor propulsion system options using equivalent technology assumptions and a consistent analysis process to permit informed trade-offs among these three options. The general approach taken for this study is to develop analytical models of advanced, two-spool ducted turbofan engines, combine them with an advanced technology airframe model, design the overall system to meet mission requirements and constraints, and assess the resulting noise, fuel consumption, and emission characteristics.

\section{Modeling and Analysis Methodology}

\section{A. Propulsion Modeling}

Propulsion system modeling is performed using NPSS (Numerical Propulsion System Simulation) ${ }^{12-14}$ for cycle analysis and performance and WATE (Weight Analysis of Turbine Engines) ${ }^{15-17}$ for aeromechanical design and weight/dimension estimates. Estimates for $\mathrm{NO}_{\mathrm{X}}$ emission indices are obtained from an empirical correlation representing an advanced, low $\mathrm{NO}_{\mathrm{X}}$ combustor. Reference 2 provides more details on this empirical $\mathrm{NO}_{\mathrm{X}}$ correlation, which was developed by NASA combustor technologists during the latter stages of NASA's Ultra- 
Efficient Engine Technology Program. All engines in the study are two-spool, separate flow turbofans designed with the same Aerodynamic Design Point (ADP) of Mach=0.8 at 35,000 ft and same Overall Pressure Ratio (OPR) of 42 at the ADP. In addition to investigating geared and direct drive architectures, two different compressor work splits are considered. The "low work" engines have a lower pressure rise across the low pressure compressor (LPC) (and a higher pressure rise across the high pressure compressor (HPC)) compared to the "high work" engines. Low fan pressure ratio (FPR) engine cycles generally require some type of variable geometry for proper operation across the flight envelope; the use of a variable area bypass nozzle is assumed in this study. Since the variable area nozzle has a weight penalty, it is only applied when necessary to achieve the desired fan surge margins throughout the operating envelope. The variation in fan drive approach, compressor work split, and fan pressure ratio results in a total of twelve different engines in the study.

Changes to the engine modeling and assumptions for this updated analysis are summarized in Table 1 . The first change is new nominal design thrust values resulting from changes in the aircraft modeling discussed in the next section. The second change is a correction to the way the bypass ratio is set for each engine design. In engine cycle design, the fan pressure ratio is usually treated as an independent variable selected by the designer. With the FPR set, the bypass ratio is usually varied to match a preselected target value for the ratio of the core flow and bypass flow jet velocities. Generally speaking, when bypass ratio is set in this manner, the same amount of energy is left in the core stream as the engine trade space is explored. (Alternatively, an extraction ratio - the ratio of the bypass nozzle to core nozzle total pressures - may be held constant to set the bypass ratio.) In Ref. 4, the jet velocities used to set bypass ratio were the actual velocities exiting the convergent nozzles. But when the nozzles are supercritical at the top-of-climb conditions, they are choked and the nozzle exit velocity is always sonic. Unintentionally, variable amounts of energy were therefore left in the core, which led to an inconsistent design space exploration. In the current study, this problem is corrected by using nozzle exit velocities ideally expanded to ambient static pressure to ensure consistency.

The definition of the nacelle geometry is also refined for the current assessment. The inlet length-to-diameter (L/D) ratio is set by the diffuser exit-to-throat area ratio as described in Ref. 18. The maximum nacelle diameter is set by the design values of engine critical mass flow ratio and drag-rise Mach number, using the methodology described in Ref. 19. This methodology sets nacelle maximum diameter based on a compromise between reasonable nacelle operating margin and low nacelle drag. As shown in Table 1, the new approach results in a nacelle-to-fan diameter ratio which is within $1 \%$ of that used in Ref. 4.

Table 1. Summary of changes to engine modeling.

\begin{tabular}{|c|c|c|}
\hline & Modeling in Reference 4 & Current Study \\
\hline Engine Thrust Sizing & $\begin{array}{l}\text { ADP: } 5,000 \mathrm{lb} \\
\text { SL, M=0.25: } 17,500 \mathrm{lb}\end{array}$ & $\begin{array}{l}\text { ADP: 5,100 lb } \\
\text { SL, } M=0.25: 18,750 \mathrm{lb}\end{array}$ \\
\hline Bypass Ratio & Set by actual jet velocity ratio at ADP & Set by ideal jet velocity ratio at ADP \\
\hline Inlet $\mathrm{L} / \mathrm{D}$ ratio & Constant 0.5 & Set by diffuser area ratio; $\sim 0.4$ \\
\hline Nacelle Maximum Diameter & 1.23 times fan diameter & 1.22 times fan diameter \\
\hline Variable Area Nozzle & $\begin{array}{l}\text { Exit areas not set properly at low } \\
\text { altitude }\end{array}$ & Low altitude error corrected \\
\hline LPT Adiabatic Efficiency & $\begin{array}{l}\text { Constant loading; efficiency function } \\
\text { of LPT cooling level }\end{array}$ & $\begin{array}{l}\text { Efficiency set by number of stages } \\
\text { and Stewart work-speed parameter }\end{array}$ \\
\hline Hot-section Cooling & $\begin{array}{l}\text { Aggressive cooling effectiveness } \\
\text { assumptions }\end{array}$ & $\begin{array}{l}\text { Cooling assumptions based on } \\
\text { current technology large engine }\end{array}$ \\
\hline Gearbox weight & $\begin{array}{l}\text { Original WATE correlation } \\
\text { (developed by Boeing) }\end{array}$ & NASA updated correlation \\
\hline
\end{tabular}

With a variable area bypass nozzle, the bypass nozzle exit area is normally varied as flight conditions change to keep the fan operating at peak efficiency. In performing the current study, it was discovered that in the previous study (Ref. 4) a user error in the NPSS solver prevented the bypass nozzle exit areas from automatically increasing at lower altitudes. Although correct at mid to high altitudes, the exit areas were somewhat smaller than they should have been near sea level. Since the engine cycle was designed using a multiple design point solution, this error 
impacted the entire cycle design and the performance everywhere, not just a low altitude. Engine noise was also affected by the smaller than desired bypass nozzle exit area. The impacts of this error (and the jet velocity ratio error noted above) are not great enough to render the previous results invalid, but they are nevertheless corrected in the current study.

In the prior work, the LPT loading was kept constant and the stage count was allowed to grow as needed to accommodate the lower spool speeds at low fan pressure ratios. This resulted in an LPT adiabatic efficiency that was essentially constant (varying slightly due to different cooling levels), but an excessive number of LPT stages for low-FPR, direct drive engines. This approach was used realizing that engines with many LPT stages would be heavy and not competitive once evaluated in an airplane sizing calculation. The current assessment uses an iterative procedure between the cycle and aeromechanical analyses (i.e., between NPSS and WATE) to determine a more appropriate LPT stage count and weight for the direct drive engines. The LPT stage count is now limited to a maximum of nine stages. This is achieved by allowing the loadings to vary, within reason, and accepting the resulting efficiency penalty. A turbine model relating loading, stage count, and efficiency developed by Warner L. Stewart ${ }^{20}$ is used for the iteration procedure. This model assumes equal stage work, equal mean blade tip speeds, and equal stator exit angles. The cycle is initially analyzed assuming three LPT stages and an efficiency of $94 \%$. An aeromechanical analysis is then performed to determine the work-speed parameter and estimate a new efficiency using the Stewart efficiency model. If the efficiency is less than 92\%, additional LPT stages are added until the efficiency is greater than $92 \%$ or the number of stages reaches the maximum of nine. The cycle analysis is then repeated with the new efficiency estimate and the results fed to the aeromechanical analysis to compute a new workspeed parameter. This process is iterated until the cycle and aeromechanical analyses are consistent.

The engine hot-section cooling assumptions were also revised. In Ref. 4, a cooling effectiveness was used to determine the cooling bleed flow rates directed to each turbine blade row, given the hot gas temperature and the maximum allowable airfoil surface temperature. Upon review, the cooling effectiveness values assumed were too aggressive for the $\mathrm{N}+1$ timeframe. In the present study, values of cooling effectiveness appropriate for a currenttechnology GE90 engine are used. The rationale is that engine temperatures and cooling technologies appropriate for a current large engine could be transferred to engines in the single-aisle thrust class by the $\mathrm{N}+1$ timeframe. The total cooling increased from about $17 \%$ to about $19 \%$ as a result of this change.

Finally, an updated weight correlation is used to estimate the weight of the gearbox system for the geared fan engines. This empirical correlation, described in Ref. 21, was developed based on weight data from over fifty rotorcraft, tiltrotor, and turboprop aircraft. Use of this correlation makes the gearbox weight methodology in this study consistent with the single-aisle open rotor study. ${ }^{7-9}$ The resulting gearbox weights are within 45 lbs of those calculated with the older methodology used in Ref 4.

\section{B. Airframe Modeling}

The basic airframe modeling approach is described in detail in Refs. 2 and 4. In general, the same approach is retained for the current study. Two areas where enhancements have been made are the baseline modeling and the aircraft sizing procedure.

As described in Ref. 2, the 737-800 (with winglets) is used to develop a baseline analytical model from which the benefits of future advanced technologies are assessed. The 737-800-like analytical model used as a starting point in the prior studies has been shown to compare favorably with published performance characteristics of the 737-800, particularly with regard to fuel consumption. ${ }^{22}$ However, over the years since the model was initially developed, new analysis tools and methods have been incorporated into the standard analysis suite. One example is an improvement in the methodology used to size vertical and horizontal tails. Another example is a more explicit accounting for propulsion system installation weight. Additionally, the core analysis tool, the Flight Optimization System (FLOPS), ${ }^{23}$ has been modified over the years, which has enabled some enhancements to the modeling "best practices." In order to incorporate these changes in the propulsion trade study, it was necessary to first apply them to the baseline vehicle and re-calibrate the model. The NASA model of the CFM56-7B-like engine used on the baseline model has also been updated. The baseline engine model used in the prior studies was incomplete and it was not possible to generate the data needed to do noise analysis. This required developing a separate CFM56-7Blike engine for noise validation. The incomplete engine model has been replaced with a new, complete NPSS model to enable a single, consistent model that can be used in multiple types of analyses. There is minimal impact of these modeling changes on the 737-800-like starting point, since by design the model is re-calibrated to match the published data. However, the new calibration factors are propagated through the rest of the study vehicles and impact the results for those vehicles.

In advanced vehicle concept and technology trade studies, a passenger load and range capability is typically specified for the design mission and all the study vehicles are sized to be able to fly that mission (under typical

4

American Institute of Aeronautics and Astronautics 
reserves and air worthiness constraints). The assumption behind this approach is that it enables a consistent comparison of multiple vehicles with the same mission capabilities. In reality, however, the off-design capabilities can be quite different. As an aircraft becomes more efficient through advanced technologies, the value of a pound of fuel as measured in range capability increases. This means that the decrement in range associated with trading that pound of fuel for more payload also increases. As a result, the range capability of the advanced, more efficient vehicles can be less for off-design, high payload missions than the baseline vehicle. This loss in capability at high payload is undesirable. It is impossible to exactly match the payload-range capability of an advanced vehicle to that of the baseline vehicle because of the fundamental difference in the impact of fuel weight changes on range. It is possible, however, to constrain the range capability of the advanced vehicle to be equal to or greater than the baseline vehicle and avoid a loss in capability. A new aircraft sizing procedure is used in this study that sets a minimum range capability of $2125 \mathrm{~nm}$ at maximum payload and matches range capability of $3250 \mathrm{~nm}$ at the nominal design payload. Maximum takeoff weight, maximum landing weight, and maximum fuel weight are iterated until the desired payload-range capabilities are met. The result of this new approach is illustrated by the payloadrange diagrams shown in Fig. 2, representing the baseline current technology aircraft and the twelve advanced vehicles modeled in the study. By imposing range performance constraints at both the maximum payload and design payload conditions, the payload-range capabilities are similar for all of the study vehicles.

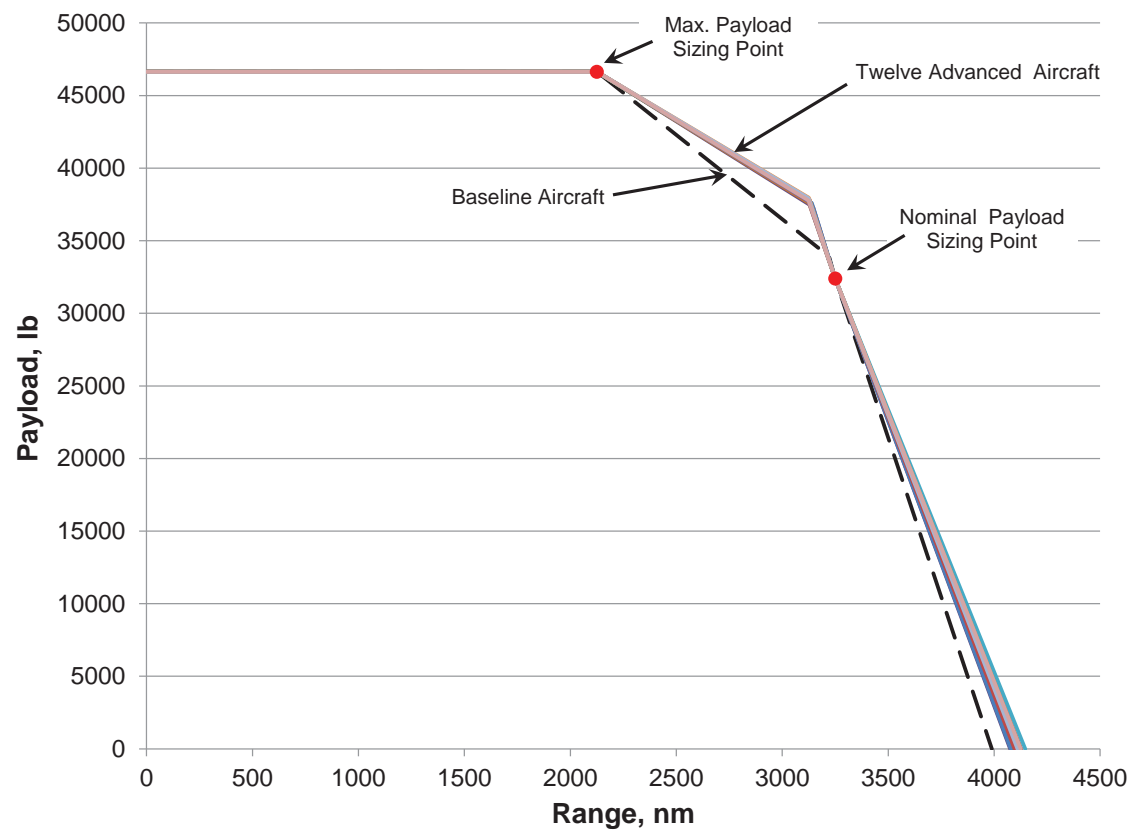

Figure 2. Comparison of payload-range capabilities for study aircraft.

\section{Noise Analysis}

Several changes were made to the noise prediction procedures described in Ref. 4. One basic difference is the use of ANOPP ${ }^{24,25}$ Level 30, which includes several upgrades and bug fixes since Level 26 (the version used in Ref. 4).

The second difference is the manner in which the takeoff trajectory is modeled. In Ref. 4, the noise abatement throttle cutback was assumed to occur at 16,000 ft from brake release. Performing the cutback at this location (well short of the Part 36 flyover noise monitor location at 21,325 $\mathrm{ft}^{26}$ ) ensured that the flyover effective perceived noise level (EPNL) noise signature consisted of the engines in their throttled, cutback state. However, in noise certification practice, the time of the noise abatement throttle cutback is often varied to minimize the flyover EPNL. The throttle cutback may be delayed until the airplane is quite near the flyover noise monitor, giving the airplane the opportunity to climb higher and reduce its noise level at the flyover point by spherical spreading effects. The tone-weighted perceived noise level (PNLT) vs. time noise history for a minimized flyover EPNL will exhibit two peaks: the first reflecting the airplane at maximum throttle, gaining altitude quickly but still short of the monitor; and the second at reduced throttle, climbing only at a four percent climb gradient, and passing over the monitor. In addition to changing the cutback location, a brief acceleration segment at $1000 \mathrm{ft}$ altitude used in Ref. 4 was omitted in favor of a constant speed climb. This also allows the airplane to achieve a higher altitude over the flyover monitor and is 
more representative of a Part 36 certification takeoff. These two modifications to the trajectory calculations result in an increase in the altitude over the flyover monitor of over $600 \mathrm{ft}$. The flyover EPNLs in this study are reduced by more than 3 EPNdB relative to the results computed using the procedures in Ref. 4.

A third difference is the use of a new hardwall fan noise analysis that is more appropriate for advanced fan designs likely to be in service in the $\mathrm{N}+1$ timeframe. In Ref. 4, the fan noise was predicted using a method developed by General Electric. ${ }^{27}$ GE's method consists of a recalibration of the original fan noise method developed for ANOPP by Heidmann. ${ }^{28}$ While the overall structure of Heidmann's original empirical method remained intact, GE adjusted the method's numerical constants to predict fan noise at levels that reflected GE's experience base with large turbofans in service just prior to 1996: the CF6-80C2, CFM56, $\mathrm{E}^{3}$, and QCSEE engines (see Ref. 27 for details). These engines have fans with relatively narrow chords, straight blades, and high pressure ratios; whereas modern fans are designed with wider chords, swept and contoured blades, and often have lower pressure ratios and tip speeds. In this study, another recalibration of the Heidmann fan noise method is used. In 2006, acoustic investigators employed by Diversitech, Inc., working under contract with NASA, obtained several scale model fan acoustic datasets collected from the NASA Glenn 9- by 15-foot Low Speed Wind Tunnel. Of particular importance were the datasets collected from scale model representations of the CF6-80E1 fan and the Advanced Ducted Propulsor fan. ${ }^{29}$ The former dataset is significant because the fan was equipped and tested with several stator sets that allowed investigations into stator sweep and lean technology. The latter dataset is significant due to its unique operation in very low fan pressure ratio regimes. It provided insight into the noise generation mechanisms of these types of fans without the masking influence of shock-related sources found in other fans operating in supersonic regimes. The fan noise prediction method based on these advanced fan designs is used in this assessment since it is more representative of modern, contoured, wide-chord fans for high bypass ratio turbofans. This method was coded into ANOPP's Heidmann fan noise prediction module in 2008, where it now resides as an informal, interim, and (currently) undocumented option. (This method is accessed in ANOPP by setting HDNMTH=4.)

The fourth difference in the noise prediction procedure is the replacement of fixed fan liner acoustic performance data with a parametrically varying fan acoustic treatment model. In Ref. 4, the benefits of fan acoustic liners were modeled by applying an acoustic suppression performance "map" of $1 / 3^{\text {rd }}$ octave band sound pressure level decrements to the predicted hardwall fan source spectra. The liner suppression map was based on measured wind tunnel data from the 22-inch diameter "Fan 1" rig in NASA Glenn's 9- by 15-foot Low-Speed Wind Tunnel. ${ }^{30}$ The most effective treatment tested in these experiments was a double degree of freedom liner applied to the inlet, interstage, and aft bypass duct areas. This level of liner suppression was deemed appropriate for use in turbofans of this class for the $\mathrm{N}+1$ timeframe. However, this approach did not account for the variability in liner effectiveness with changes in inlet and bypass duct dimensions. Inlet diameter and length, and aft bypass exhaust duct height and length are important variables in liner performance, and they vary from engine to engine in this turbofan design space exploration. ANOPP's built-in empirical acoustic treatment model ${ }^{31}$ reacts properly to changes in these dimensions, but it underpredicts the level of liner performance that would be expected by the $\mathrm{N}+1$ timeframe. Therefore, a hybrid approach is used in this assessment. ANOPP's built-in treatment prediction method is used since it reacts properly to changes in treatment dimensions. But, the inlet and exhaust duct length inputs are deliberately exaggerated by ten percent. This artificial increase in duct lengths results in predicted liner spectra that match the advanced liner performance levels measured in the rig tests, while retaining the dependency on geometry. In other words, the duct length inputs are used as technology calibration factors to force the liner prediction method to match the performance of newer, higher performance liners.

Two modifications were made to the way propagation effects are computed. In 2012, NASA began discussions with ICAO's Noise Technology Independent Expert Panel and contributed to a related task. ${ }^{32}$ Over the course of the discussions, panel members noted that we used a value for the ground flow resistivity (an important parameter in ground reflections, calculated in ANOPP via the Chien-Soroka method ${ }^{33}$ ) in our previous studies that was at the high end of the range typical for grass-covered ground. Regulations in the ICAO Environmental Technical Manual ${ }^{34}$ permit the microphones to be located in areas of grass as high as $8 \mathrm{~cm}$. In this study, the value for the flow resistivity was reduced from $485 \mathrm{slug} / \mathrm{s}-\mathrm{ft}^{3}$ to $291 \mathrm{slug} / \mathrm{s}-\mathrm{ft}^{3}$ (the approximate minimum measured for grass-covered ground ${ }^{35}$ ) reducing the strength of ground reflections. The second propagation effect modification is a credit taken at the lateral observer for excess ground attenuation. For observers laterally displaced on a sideline relative to the runway, there are additional propagation effects that should be considered. The attenuation is due to differences in ground effects (i.e., in surface absorption and reflections), meteorological effects (such as wind and atmospheric gradients), and effects due to the airplane configuration (such as engine-airframe shielding and reflections). These effects are often collectively known as lateral attenuation or excess ground attenuation. An empirical curve recommended by the $\mathrm{SAE}^{36}$ was used to reduce the lateral EPNL to account for these effects. At the lateral sideline distance of 1476 $\mathrm{ft}$, and where the lateral EPNL is highest, the excess ground attenuation is just over 1 EPNdB. 
The final noise analysis difference is the elimination of advanced airframe noise reduction technologies. In Ref. 4 , reductions in the predicted levels of landing gear, flap, and slat noise were assumed that reflected use of airframe technologies such as gear fairings, continuous moldline flexible flap links, and slat cove fillers, respectively. During the dialogues with the ICAO Panel mentioned in the preceding paragraph, members advised NASA that these advanced airframe noise reduction technologies are too immature to be in use by the $\mathrm{N}+1$ timeframe. Therefore, in this study all airframe source noise is computed by ANOPP using the Fink method ${ }^{37}$ without adjustment.

\section{Analysis Results}

\section{A. Engine Design}

Overall impacts of the changes to the engine design and modeling assumptions are shown graphically in Figs. through 6 for key propulsion characteristics. The results from Ref. 4 are shown as faded lines in the figures. From Fig. 3 it is clear that the new engine modeling has reduced engine weight across all twelve of the study engines. The decrease is largest for the direct drive engines due to the new LPT design approach used, which limits the number of LPT stages and the growth in weight of the direct drive engines at low FPR. Even though the weight penalty for low FPR direct drive engines is less now, it is still higher than for the geared engines. (Note that in Ref. 4 the direct drive, FPR=1.4 engines were considered impractical designs due to design ground rules resulting in 13 to 15 LPT stages, and the results for these designs were shown as dashed lines in the figures. With the current approach, the number of LPT stages is limited to nine and these designs are now practical, although heavy. The geared, FPR=1.3 engine was also previously considered impractical due to integration issues for an under-wing installation. However, since the conclusion of the earlier study, a more detailed UHB engine integration trade study was conducted, which found that an engine with a nacelle diameter of $9.4 \mathrm{ft}$ could be integrated on the ASAT airframe. Since the FPR=1.3 case in this study has a nacelle diameter of $9.3 \mathrm{ft}$, this engine is now considered a potential practical design.)

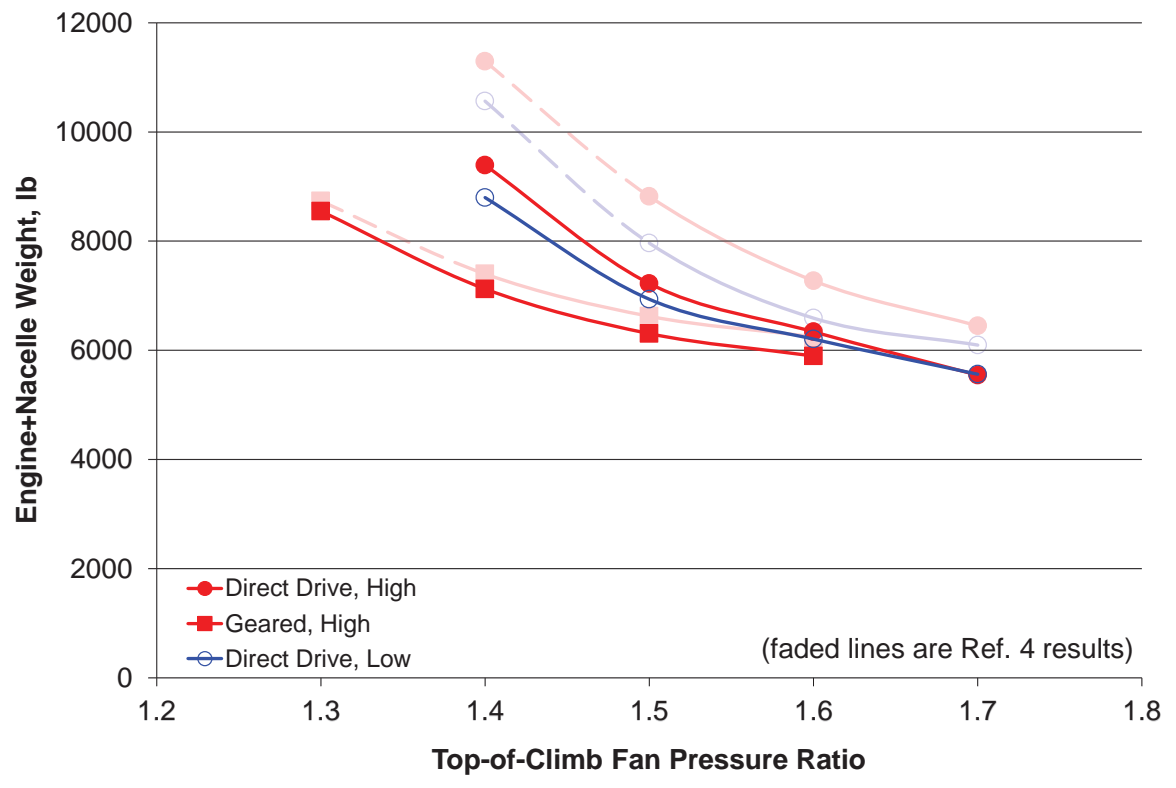

Figure 3. Variation of engine+nacelle weight with engine type and design fan pressure ratio.

Because the engine design thrust conditions are not the same as in the previous work, a comparison of engine thrust-to-weight is more appropriate than absolute weight. In Fig. 4, the thrust-to-weight at the rolling takeoff condition (a key engine sizing point) is compared. The improvement in thrust-to-weight ratio for the new designs is significant, on the order of $25 \%$ for the direct drive engines and $10 \%$ for the geared engines.

Although the new engines are lighter, the thrust specific fuel consumption (TSFC) is higher (see Fig. 5). The increase in TSFC is due to changes in the cooling assumptions, the LPT efficiency model, and the jet velocity ratio. The slope of TSFC with respect to FPR is also steeper, effectively increasing the TSFC benefits of lowering FPR. This is due to the switch from actual jet velocity ratio to ideal jet velocity ratio to set bypass ratio, which has the effect of lowering the bypass ratios at high FPR. Whereas previously the geared engines had slightly higher TSFC than their direct drive counterparts, with the changes in engine modeling the high work, geared and low work, direct drive TSFC values are essentially equal for a given FPR. The geared engines have a weight advantage, however, as 
shown in Fig. 3 and Fig. 4. Another observation is that the TSFC versus FPR trend exhibits a more non-linear behavior than in the previous analysis. The advanced engines in this study have TSFC values which are $16-27 \%$ below that of the baseline CFM56-7B-like engine. In comparison, the projected TSFC improvements for the new CFM LEAP-1 and Pratt \& Whitney PW1100G engines are around 15\%. ${ }^{38}$

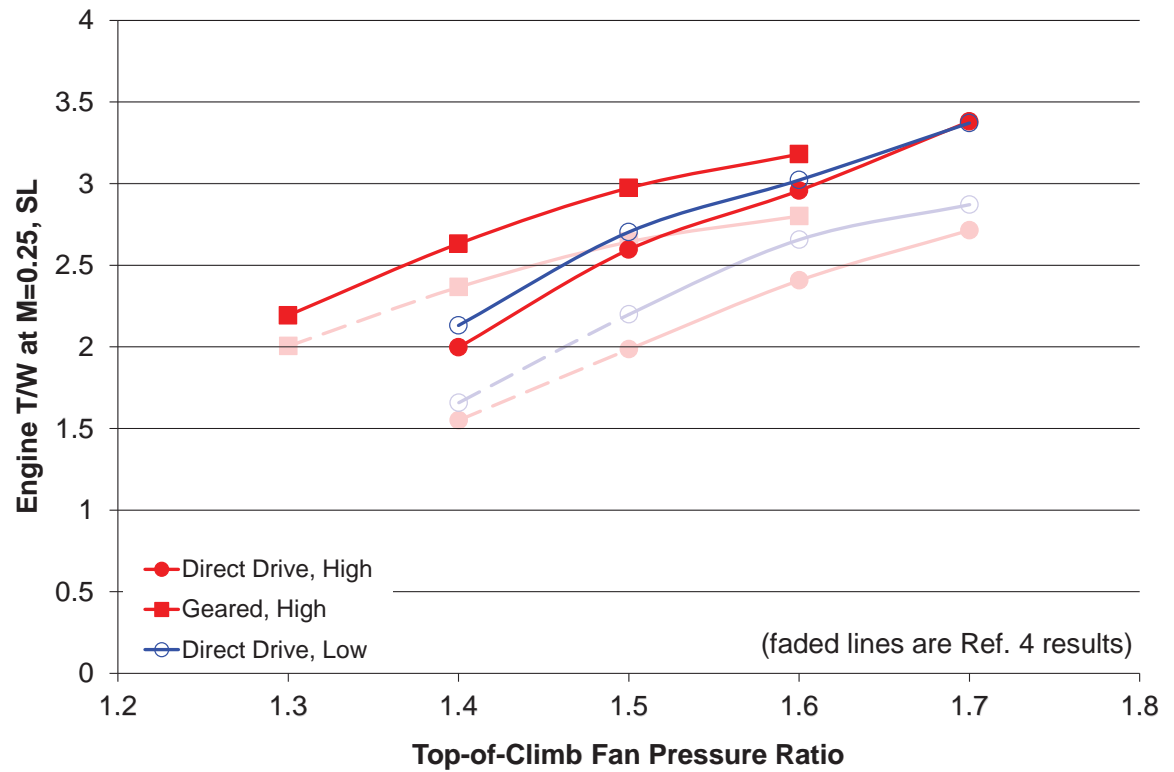

Figure 4. Variation of engine thrust-to-weight ratio with engine type and design fan pressure ratio.

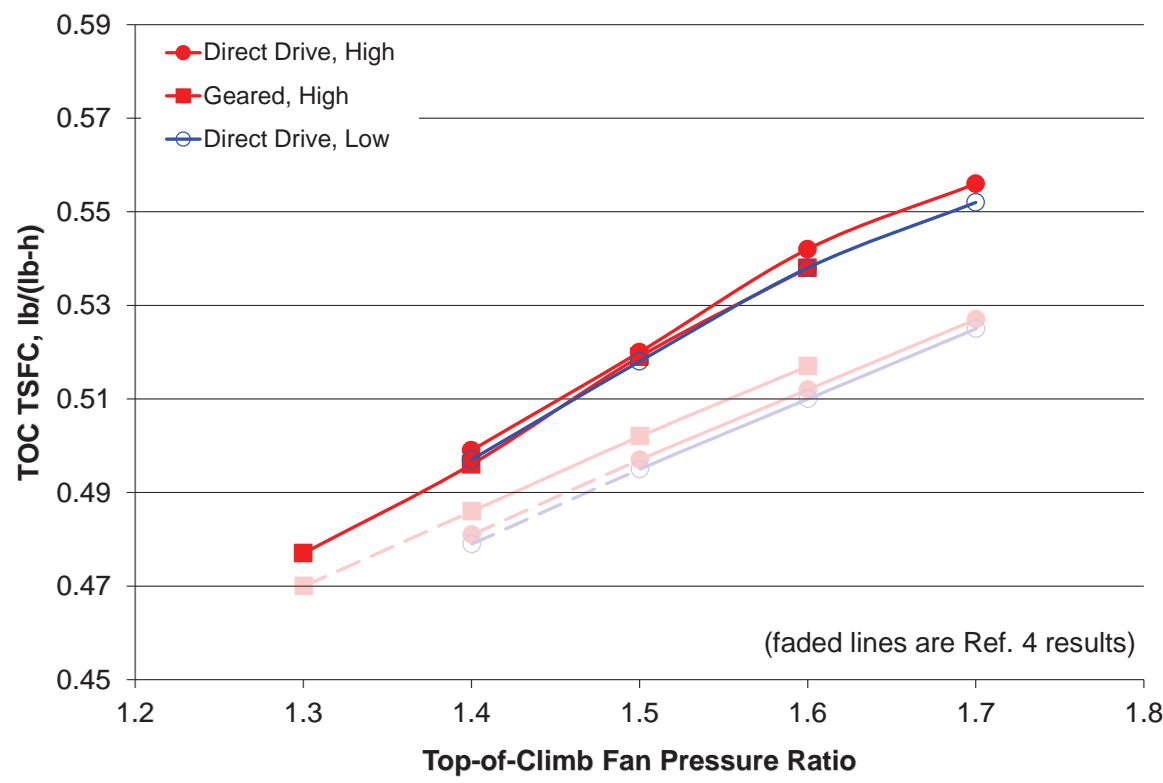

Figure 5. Variation of TSFC with engine type and design fan pressure ratio (Mach=0.8; 35,000 ft).

The trade between engine weight and efficiency as the fan pressure ratio is decreased is clearly evident by comparing Fig. 3 and Fig. 5. Decreasing FPR is beneficial for TSFC, but comes with an increase in engine weight. The magnitude of that weight penalty depends on the engine architecture used, with the high work, geared architecture resulting in the smallest weight growth.

Landing-Takeoff (LTO) $\mathrm{NO}_{\mathrm{X}}$ is regulated as an engine parameter, " $\mathrm{D}_{\mathrm{p}} / \mathrm{F}_{\mathrm{oo}}$," where $\mathrm{D}_{\mathrm{p}}$ is the grams of $\mathrm{NO}_{\mathrm{X}}$ emitted over a standard LTO cycle (by a single, uninstalled engine) and $\mathrm{F}_{\text {oo }}$ is the rated output at sea-level, static conditions in kilonewtons. This parameter is defined by ICAO and used in FAR Part 34 for engine certification. ${ }^{39}$

8

American Institute of Aeronautics and Astronautics 
The $\mathrm{D}_{\mathrm{p}} / \mathrm{F}_{\mathrm{oo}}$ values for the study engines are presented in Fig. 6 . As with the previous study, there is a general increase in LTO $\mathrm{NO}_{\mathrm{X}}$ as the FPR is increased and minimum LTO $\mathrm{NO}_{\mathrm{X}}$ occurs at FPR=1.3. The new engines exhibit a sharp increase in $\mathrm{LTO} \mathrm{NO}_{\mathrm{x}}$ between $\mathrm{FPR}=1.4$ and $\mathrm{FPR}=1.5$. This is due primarily to the transition from a variable to a fixed area bypass nozzle starting with the FPR=1.5 case. For comparison, a FPR=1.5 cycle employing a variable area nozzle was also investigated. The resulting engine produces a slightly lower $\mathrm{LTO} \mathrm{NO}_{\mathrm{X}}$ value, along the FPR=1.3 and FPR=1.4 trend line. However, the engine's required area variability is not significant enough to justify the weight penalty associated with a variable area nozzle. The overall impact of FPR on $\mathrm{LTO} \mathrm{NO}_{\mathrm{X}}$ is rather large, with $\mathrm{D}_{\mathrm{p}} / \mathrm{F}_{\mathrm{oo}}$ of the FPR=1.7 engines being approximately twice as much as for the FPR=1.3 engine. The predicted $\mathrm{D}_{\mathrm{p}} / \mathrm{F}_{\mathrm{oo}}$ is compared to the regulatory limits set by the ICAO Committee on Environmental Protection (CAEP) in Fig. 7. The NASA $\mathrm{N}+1$ LTO $\mathrm{NO}_{\mathrm{X}}$ goal of $60 \%$ below CAEP6 is met for engines with a FPR of 1.5 and below.

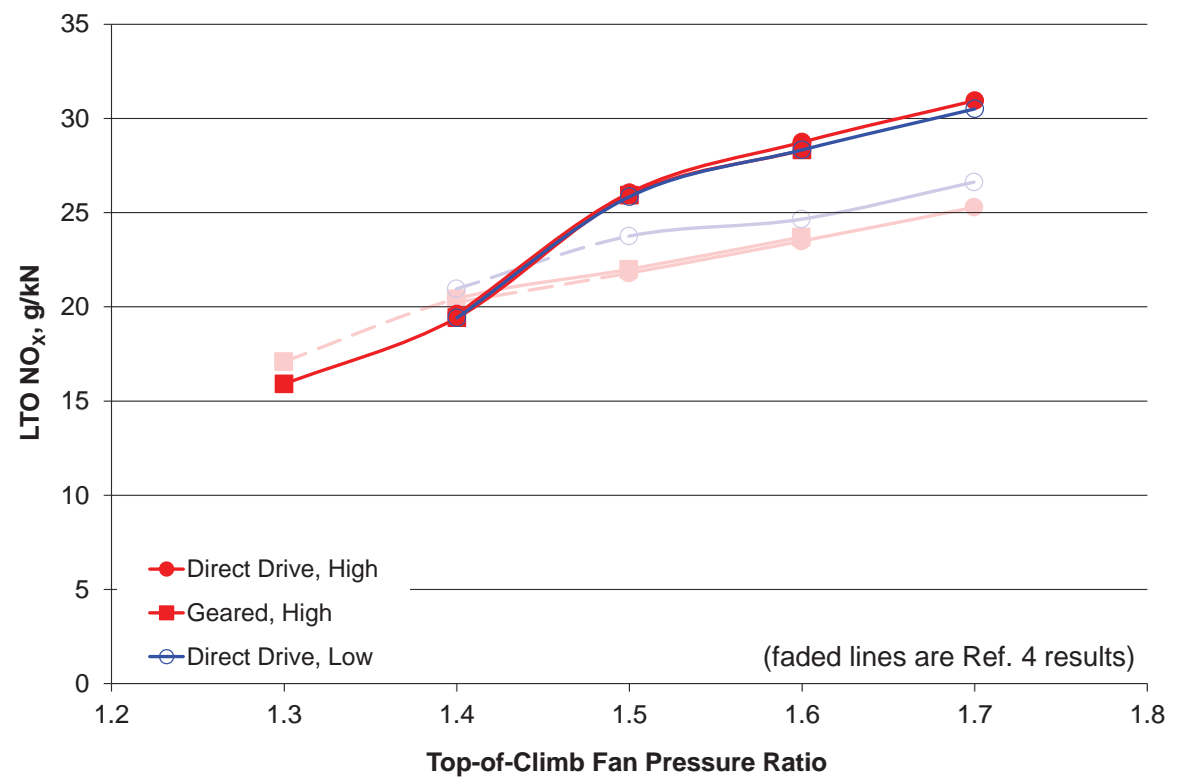

Figure 6. Variation of Landing-Takeoff $\mathrm{NO}_{\mathrm{X}}$ emissions with engine type and design fan pressure ratio.

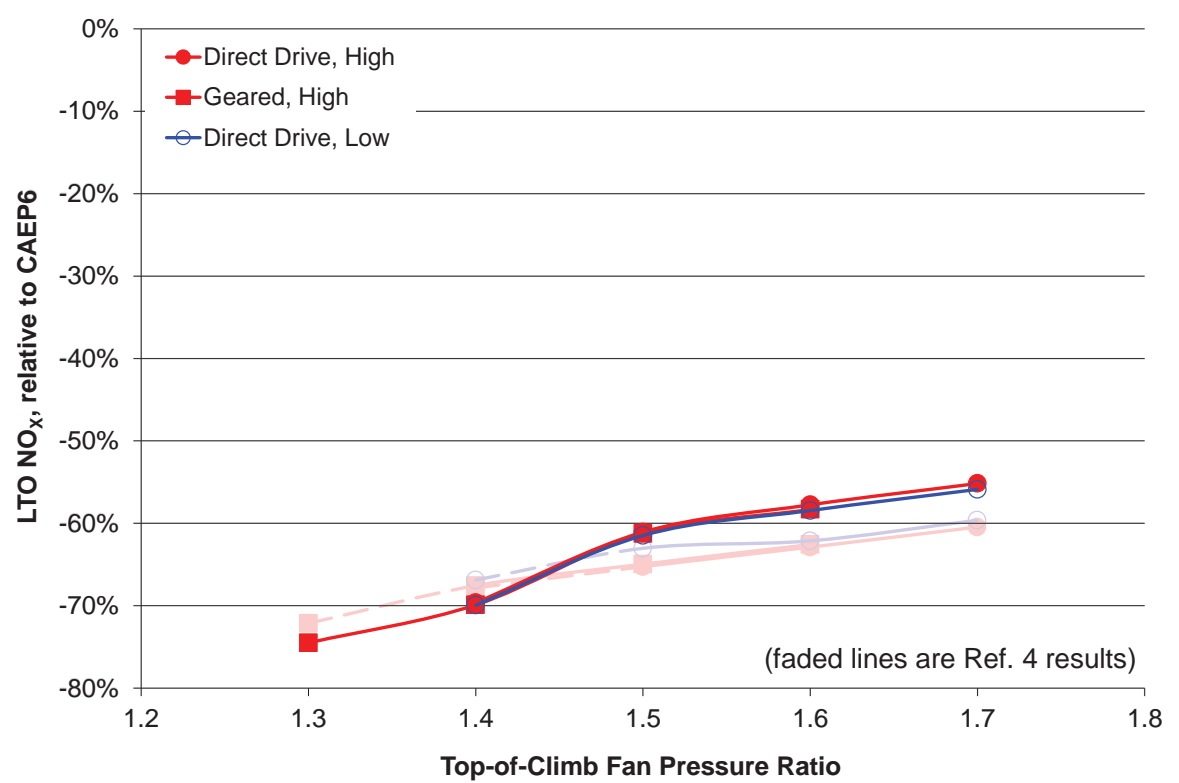

Figure 7. Variation of LTO $\mathrm{NO}_{\mathrm{X}}$ margin relative to CAEP6 limits with engine type and design fan pressure ratio. 


\section{B. Aircraft Sizing and Performance}

Each of the advanced engines was combined with an advanced single-aisle transport, "ASAT," airframe to assess the impacts of the engine characteristics on system level parameters such as maximum takeoff weight, fuel consumption, emissions, and noise. Results for key parameters are compared to those in Ref. 4 in the figures below, with the results of the previous study shown as faded lines. The aircraft sizing and performance results are shown here in relative terms, compared to a baseline technology vehicle that has the technology level of the 737-800 (1998 entry-into-service) but is redesigned for the study mission requirements.

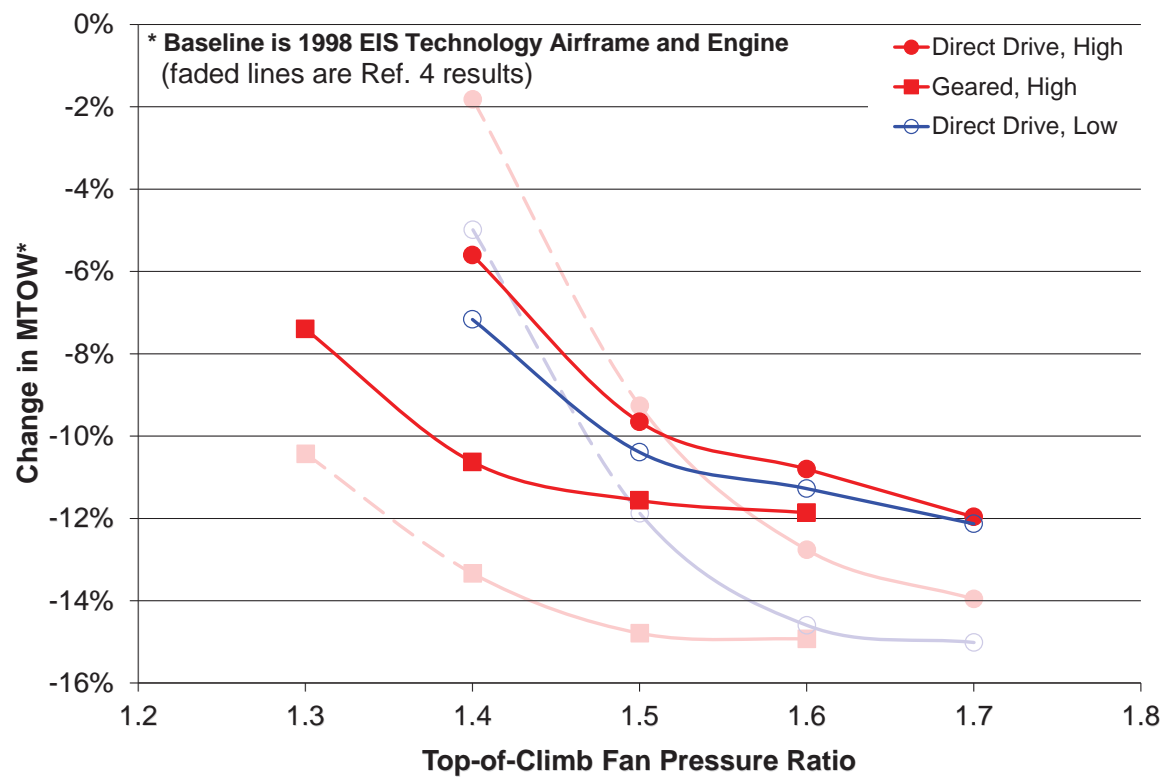

Figure 8. Reduction in Maximum Takeoff Weight as a function of engine type and design fan pressure ratio.

The overall technology benefit for maximum takeoff weight (MTOW) is generally less in this study than in the prior analysis, as seen in Fig. 8. This can be attributed to the changes in the aircraft sizing approach. In particular, the updated advanced vehicles are larger and heavier than before in order to meet the minimum $2125 \mathrm{~nm}$ range capability at the maximum payload condition. For the lowest FPR direct drive cases, the greatly reduced engine weight compared to Ref. 4 offsets the weight increase due to the aircraft sizing approach and slightly lower MTOWs are obtained. The maximum reduction in MTOW of approximately $12 \%$ occurs for the low work, direct drive $\mathrm{FPR}=1.7$ engine.

Reductions in block fuel consumption for the design mission $(3250 \mathrm{~nm})$ are shown in Fig. 9. The airframe modeling changes have only a slight impact on the relative fuel consumption reductions. Therefore, changes in engine modeling are the primary source of the differences between the current results and those of Ref. 4. For the direct drive architecture, the high FPR cases are not as good as before, whereas the low FPR cases are better. As a result, the fuel-optimum FPR for the direct drive engines has shifted from 1.6 to 1.5 (and the penalty of going down to a FPR of 1.4 is smaller). This shift is due to the increased sensitivity of TSFC to FPR combined with the decreased sensitivity of weight to FPR. As FPR is decreased, weight is not growing as fast as before and TSFC is dropping faster. The fuel-optimum FPR for the high work, geared engine architecture is also lower than the previous study, moving from a FPR of 1.5 to 1.4. The minimum block fuel for the geared engine architecture is approximately $2 \%$ lower than for the direct drive architecture and $29 \%$ below the fuel consumption of the baseline vehicle. The $29 \%$ reduction in block fuel is slightly short of the $33 \%$ NASA N+1 goal for fuel consumption.

Previously it was estimated that for a FPR of 1.55 and above the direct drive architecture would result in lower fuel burn than a geared engine. For the current results, there is no clear "crossover" point between the geared and direct-drive engines. Despite the similar fuel burn results at fan pressure ratios up to 1.6, the reasonableness of a geared architecture for fan pressure ratios greater than 1.5 is questionable due to resulting gear ratios that can make the gearbox impractical. 


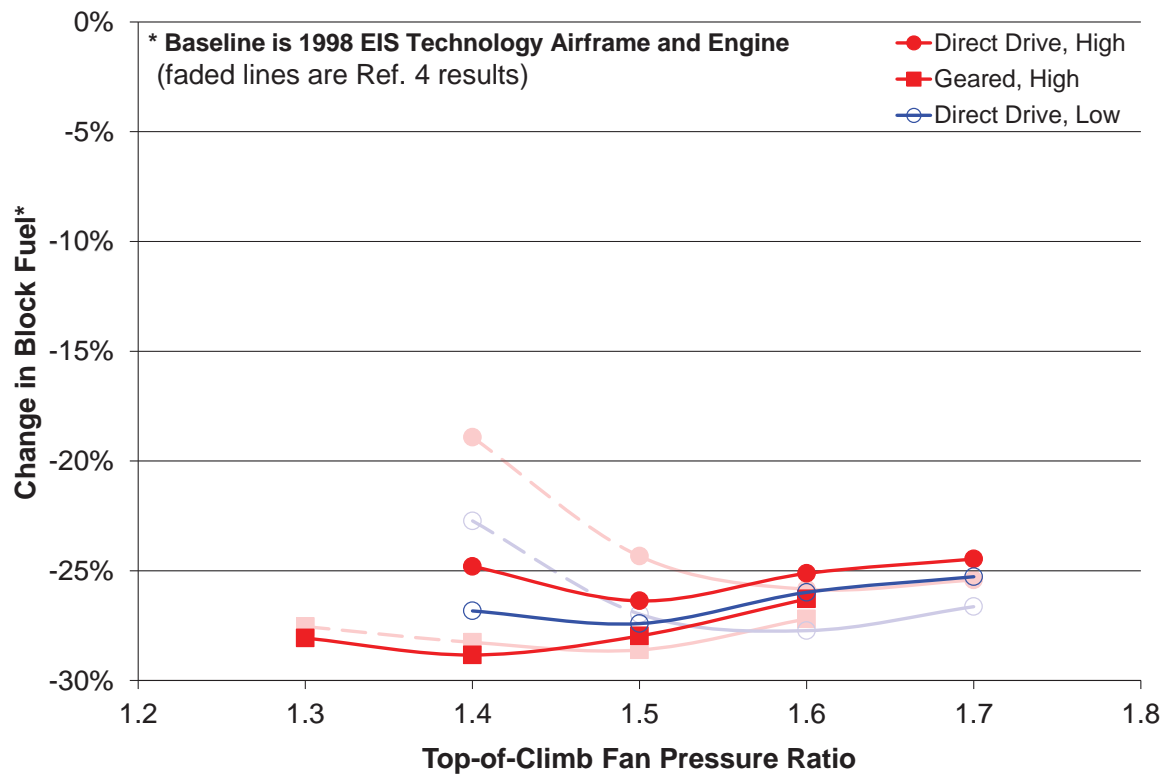

Figure 9. Reduction in block fuel as a function of engine type and design fan pressure ratio.

As evident from comparing Fig. 5 and Fig. 9, the most fuel efficient engine does not necessary lead to the most efficient airplane at the system level. In addition to an engine weight penalty as FPR is decreased (Fig. 3), there are also other penalties that tend to counter the fuel efficiency benefits of low FPR. The main penalties are separated out in Fig. 10 and Fig. 11, for the high work, geared and low work, direct drive architectures respectively. In both figures, the bottom line on the graph represents an ideal case in which only the performance of the engine is changed as FPR decreases, while the size and weight is held fixed. The penalties associated with the engine size and weight changes are then incrementally applied. The first penalty applied is the effect of FPR and engine diameter on engineout drag. Although this has a small negative impact on takeoff performance, resulting in a slightly larger engine to meet the takeoff requirements, the impact on the design mission fuel burn is negligible. The second penalty applied is the impact of nacelle diameter and length on the required landing gear length. Required landing gear length is estimated based on a minimum ground clearance of 18 inches as well as no nacelle impact in the case of nose gear collapse (see Ref. 2 for details). Although there is a significant increase in the landing gear length as the FPR is decreased, the overall impact of the additional landing gear weight on fuel consumption is relatively minor for the models in this study. The two most important penalty areas are the engine weight and the nacelle drag. For the direct drive engine, the impacts of engine weight and nacelle drag are of similar magnitude. For the geared engines, the weight growth with decreasing FPR is smaller (Fig. 3) and as a result nacelle drag is the largest penalty area. These results indicate that technologies to mitigate engine weight growth and nacelle drag are key to capturing the fuel consumption benefits of low FPR engines. In addition, having accurate prediction methods for these parameters is important in determining the optimum engine FPR for fuel efficiency. For example, the nacelle drag model used in this study (described in Ref. 2) results in a nacelle drag that is approximately proportional to nacelle diameter squared. A larger or smaller sensitivity of nacelle drag to FPR could easily shift the estimated fuel-optimum FPR. 


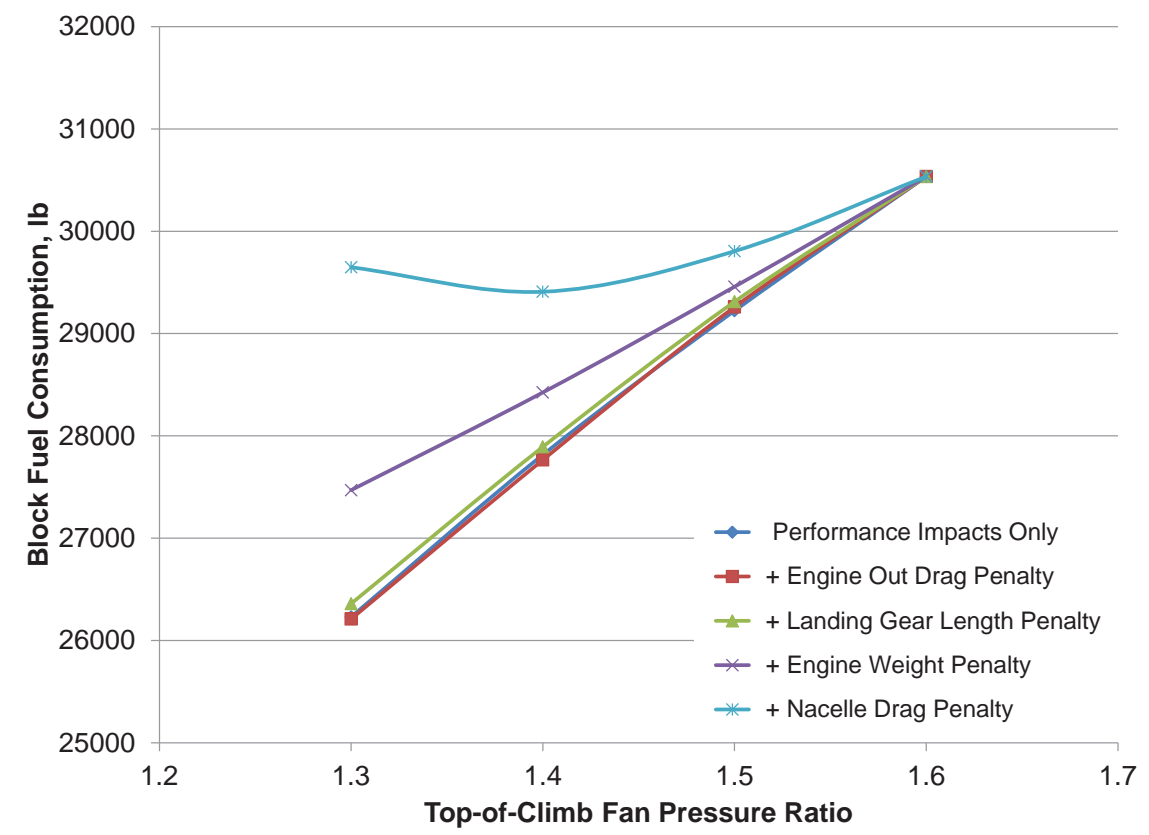

Figure 10. Penalty sensitivities for high work, geared engines.

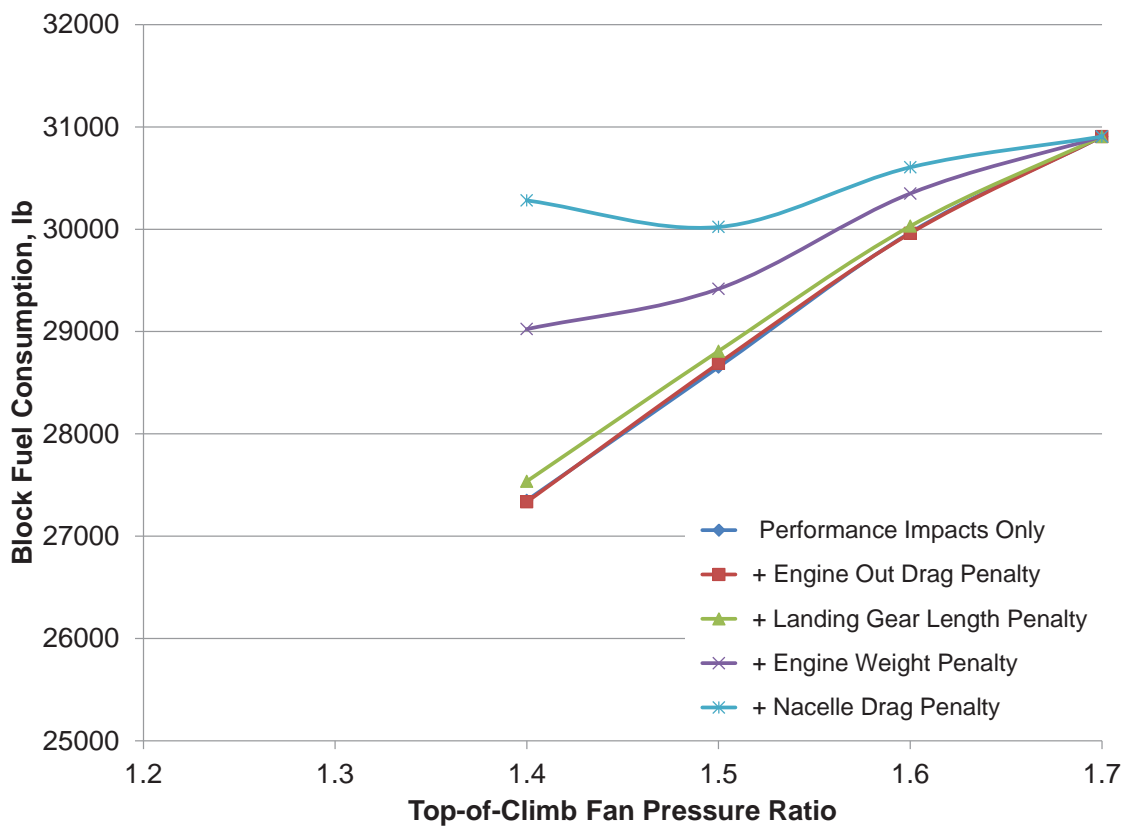

Figure 11. Penalty sensitivities for low work, direct drive engines.

The trends in block $\mathrm{NO}_{\mathrm{X}}$ (total $\mathrm{NO}_{\mathrm{X}}$ emitted over the complete design mission) are similar for the current analysis and the previous study (see Fig. 12). The reductions in block $\mathrm{NO}_{\mathrm{X}}$ relative to the baseline are due to both a reduction in fuel consumption and a reduction in the $\mathrm{NO}_{\mathrm{X}}$ emission index (EI) associated with the use of advanced, low $\mathrm{NO}_{\mathrm{X}}$ combustors. The absolute amount of $\mathrm{NO}_{\mathrm{X}}$ emitted for the current advanced vehicles is actually slightly higher than for those in Ref. 4. The decrease in the relative $\mathrm{NO}_{\mathrm{X}}$ emissions seen in Fig. 12 is attributable to changes in the $\mathrm{NO}_{\mathrm{X}}$ characteristics of the updated baseline CFM56-7B-like engine. The minimum block $\mathrm{NO}_{\mathrm{X}}$ of $66 \%$ below the baseline value occurs for the low work, direct drive architecture with a FPR of 1.7. Since the analysis reported in Ref. 4 was conducted, the Fixed Wing Project has added cruise $\mathrm{NO}_{\mathrm{X}}$ emissions as a system level metric. Reductions in cruise $\mathrm{NO}_{\mathrm{X}}$ emissions are shown in Fig. 13. As with block $\mathrm{NO}_{\mathrm{X}}$, cruise $\mathrm{NO}_{\mathrm{X}}$ is minimized with high FPR. All of 
the cases exceed the $\mathrm{N}+1$ goal of a $55 \%$ reduction in cruise $\mathrm{NO}_{\mathrm{x}}$, and the $\mathrm{N}+2$ goal of $70 \%$ reduction is exceeded for engines with a FPR of 1.5 and greater.

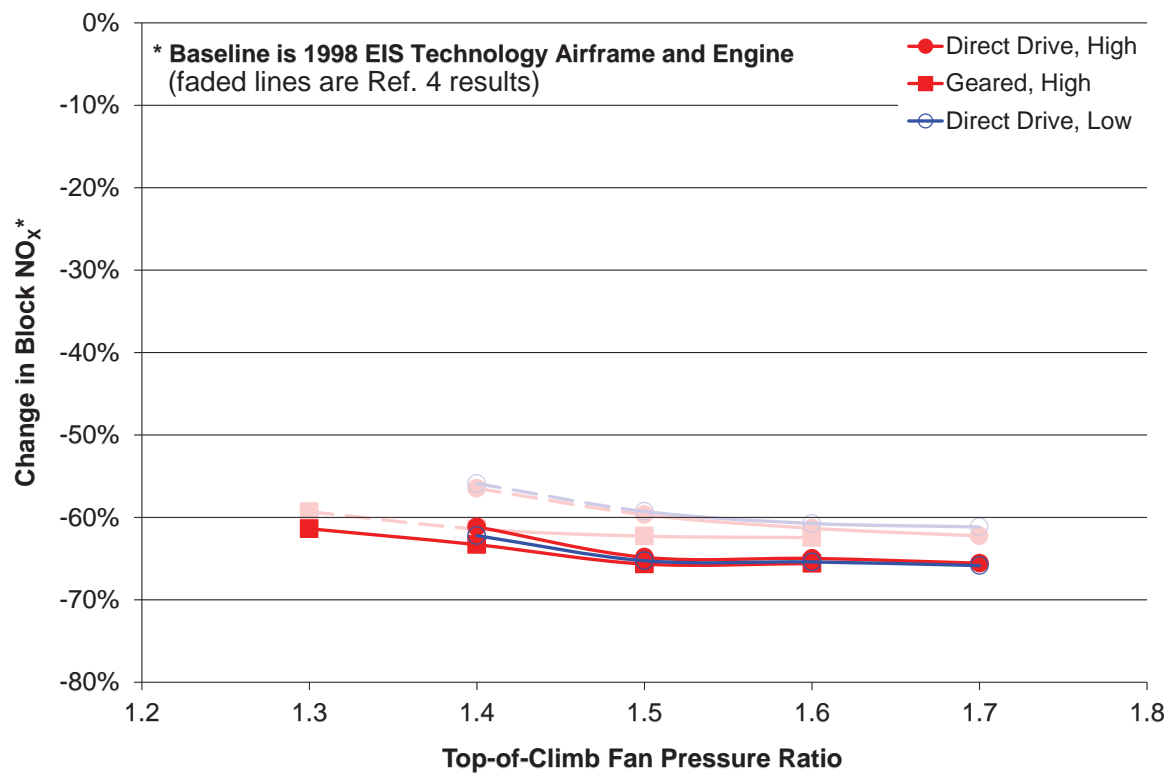

Figure 12. Reduction in block $\mathrm{NO}_{\mathrm{X}}$ emissions as a function of engine type and design fan pressure ratio.

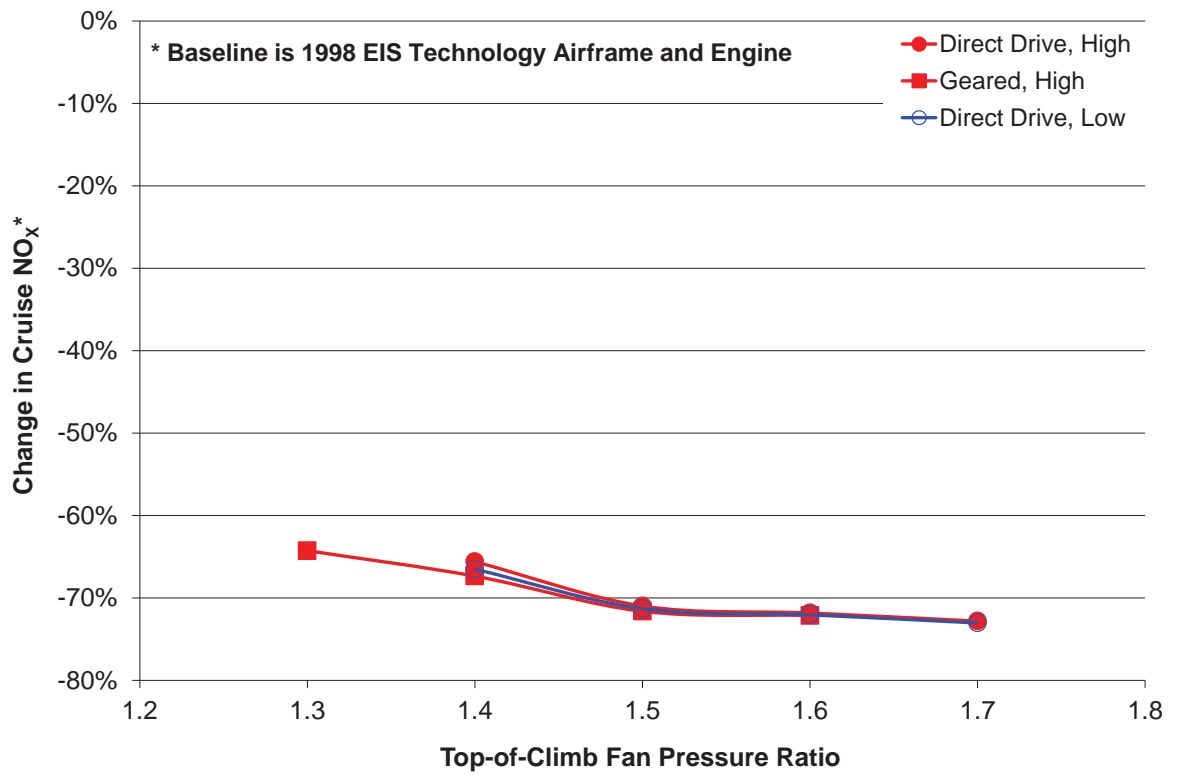

Figure 13. Reductions in cruise $\mathrm{NO}_{\mathrm{X}}$ emissions as a function of engine type and design fan pressure ratio.

The trends in aircraft LTO $\mathrm{NO}_{\mathrm{X}}$ (estimated $\mathrm{NO}_{\mathrm{X}}$ emissions per LTO cycle) shown in Fig. 14 generally follow the trends in engine $D_{p} / F_{\text {oo }}$ shown in Fig. 6. The aircraft LTO emissions are impacted by the normalized $\mathrm{NO}_{\mathrm{X}}$ characteristics of the engine $\left(\mathrm{D}_{\mathrm{p}} / \mathrm{F}_{\mathrm{oo}}\right)$ as well as the sized engine thrust. The difference between the current and previous analysis is somewhat larger for aircraft LTO emissions than for $\mathrm{D}_{\mathrm{p}} / \mathrm{F}_{\mathrm{oo}}$ due to the changes in the aircraft sizing procedure, which result in higher thrust engines and therefore more $\mathrm{NO}_{\mathrm{X}}$ emissions. 


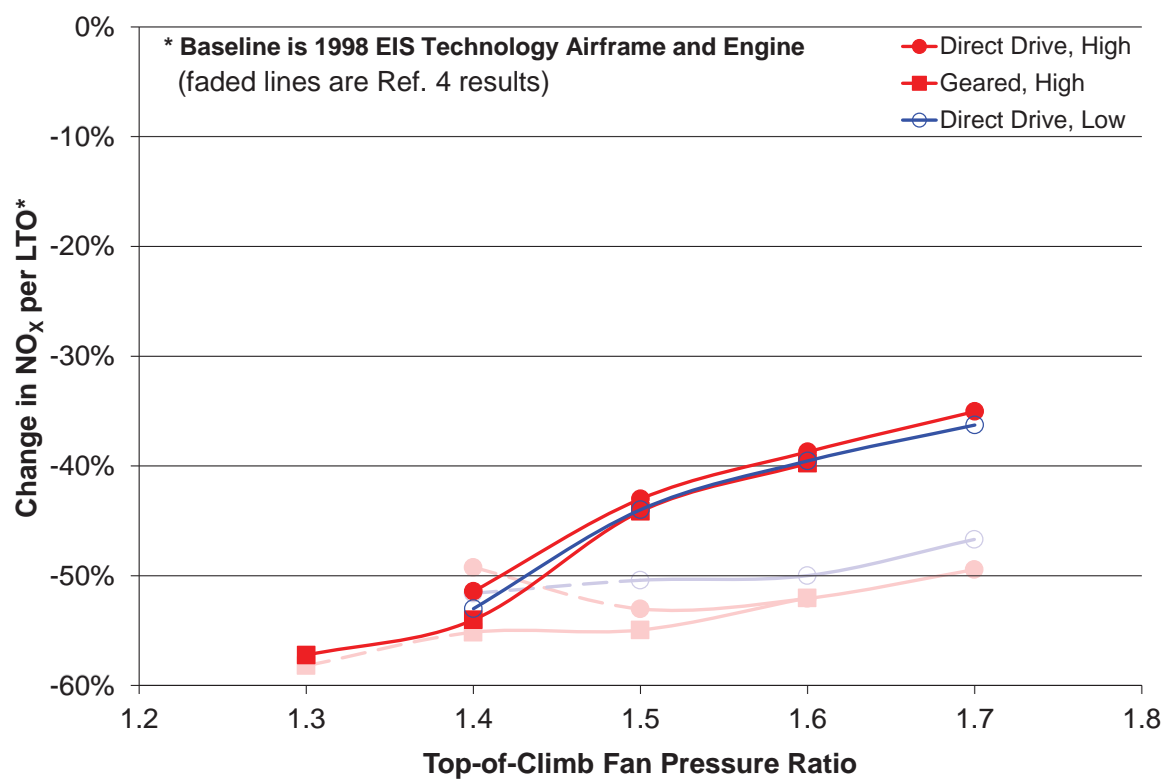

Figure 14. Reduction in LTO NO $(\mathrm{Xb}$ per LTO cycle) as a function of engine type and design fan pressure ratio.

\section{Noise Assessment}

Noise benefits for the ASAT configurations are shown in Fig. 15. The noise results are expressed in terms of the cumulative noise margin; i.e., the difference between the certification limit associated with the MTOW of the vehicle and the algebraic sum of the lateral, flyover, and approach noise levels. The noise reduction estimates from Ref. 4 are also shown with faded lines for comparison. The changes in the noise analysis have changed both the magnitude of the predicted noise and the trends with fan pressure ratio.

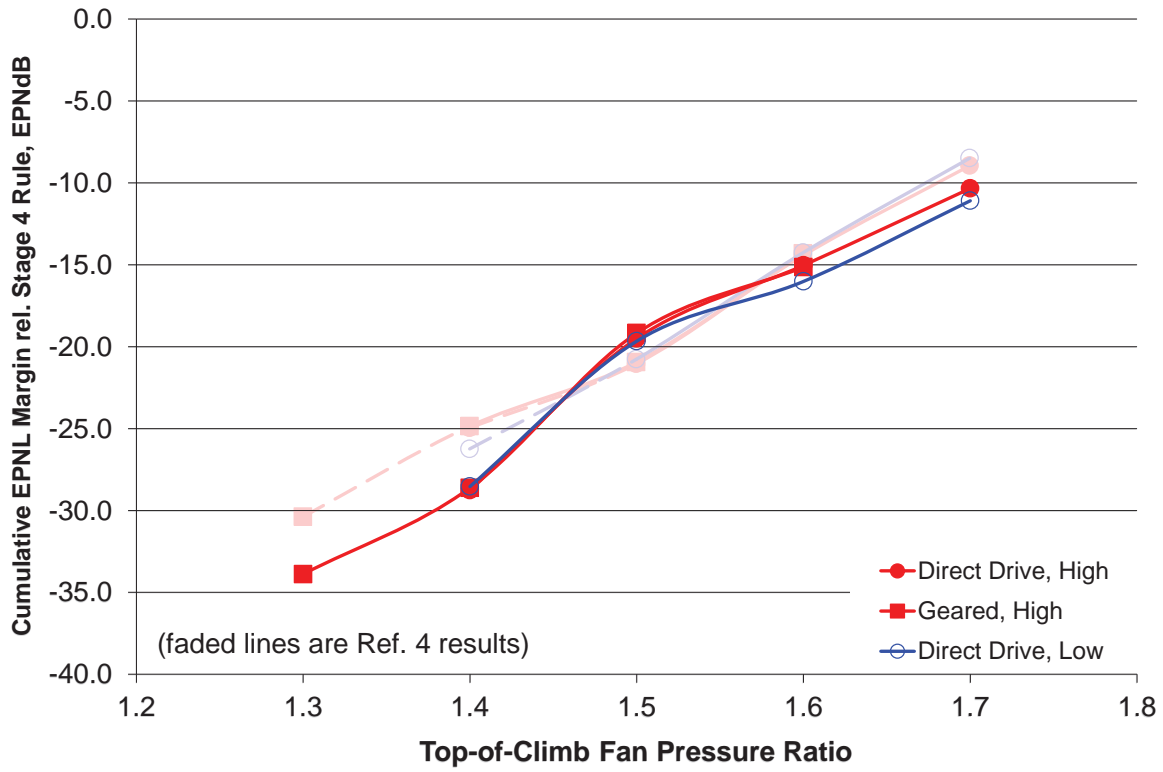

Figure 15. Estimated cumulative margin to Stage 4 as a function of engine type and design fan pressure ratio.

The largest changes relative to the previous study are for the flyover and approach EPNLs, and are due to the higher flyover altitudes with cutback optimization (a noise benefit) and the removal of the airframe noise reduction technologies (a noise penalty), respectively. These competing effects have tended to cancel each other on a cumulative noise basis. An examination of the approach EPNLs reveals that propulsion noise falls enough with 
decreasing design FPR that the approach EPNL converges on an airframe noise limit, or a "floor." Even with the elimination of airframe noise reduction technologies and the corresponding increase in airframe noise, however, fan and engine core noise still play a role in the overall approach EPNL at design FPRs as low as 1.3. Also apparent in Fig. 15 is a difference in the slope of the trend lines compared to the previous study, particularly between FPRs of 1.4 and 1.5. This is partly due to larger nozzle exit areas (an error corrected in this study) for the turbofans having variable bypass nozzles ( $\mathrm{FPR}=1.3$ and $\mathrm{FPR}=1.4$ ). Also contributing to the changes in slope is the new fan noise prediction method (described in Section III-C). The new method places greater emphasis on the fan pressure rise and airflow than on the fan helical tip speed, and although predicted fan noise decreases with design pressure ratio, neither method's predictions fall steadily or linearly. For the lower FPR turbofans where jet noise and fan noise are greatly reduced, the engine core noise becomes an important noise source. Improved core noise modeling methods calibrated to modern, high-pressure cores are therefore needed to more accurately model core noise for advanced turbofans.

\section{Summary}

Over the past several years, NASA has conducted numerous trade studies related to propulsion options for an advanced single-aisle transport. During the course of these studies, refinements and enhancements have been made to the analysis procedures. Additionally, feedback has been obtained from industry partners that has resulted in improved assumptions and engine design guidelines. In this paper, a previously conducted fan pressure ratio trade study for direct drive and geared turbofans has been revisited using the latest analysis procedures and assumptions.

As in the past, the optimum fan pressure ratio has been found to be dependent on the metric of interest. Aircraft weight and total $\mathrm{NO}_{\mathrm{x}}$ emissions continue to be minimized with high fan pressure ratio. Airport area concerns of noise and LTO $\mathrm{NO}_{\mathrm{X}}$ are still minimized with low fan pressure ratio. The optimum fan pressure ratio for fuel efficiency has decreased in the current analysis. This can be traced to a decrease in weight penalties associated with reducing FPR and an increase in TSFC benefits. The shift in fuel-optimum FPR has reduced the trade-off between minimum noise and minimum fuel consumption engines. The noise of the minimum fuel consumption vehicle (geared, FPR=1.4 case) is 4.8 EPNdB higher (cumulative) than the lowest noise vehicle (geared, FPR=1.3 case). Conversely, the fuel consumption of the minimum noise vehicle is only $1 \%$ higher than the minimum fuel consumption vehicle.

As in previous studies, the lowest fuel consumption obtained for the direct drive, low work engine architecture is slightly more than the best obtained with the high work, geared architecture. Even though the fuel consumption of fuel-optimum direct drive engine is only 2\% higher than for the fuel-optimum geared engine, the noise is $9 \mathrm{EPNdB}$ higher (cumulative) because optimum fuel consumption occurs at a higher FPR for the direct drive engines. This assessment of direct drive and geared turbofans is based on the same technology assumptions for both engine types. An engine manufacturer's own suite of technologies could tilt the results more in favor of one type or the other. In addition, airframe manufacturers could place certain requirements on the engine that would influence the propulsion choice. The engine ultimately selected for any future advanced single-aisle aircraft will depending on many factors beyond those considered here.

The aircraft in this study provide a path for meeting or exceeding the NASA $\mathrm{N}+1$ noise and $\mathrm{NO}_{\mathrm{x}}$ emissions goals. Noise reductions of up to 33.9 EPNdB below Stage 4 are predicted (goal of 32 EPNdB). The predicted engine LTO $\mathrm{NO}_{\mathrm{X}}$ is up to $74 \%$ below CAEP6 (goal of $60 \%$ ) and the cruise $\mathrm{NO}_{\mathrm{X}}$ emissions are up to $73 \%$ below the current technology baseline (goal of 55\%). However, meeting the fuel consumption goal will require additional technologies beyond those assumed in this study. The best fuel consumption obtained is a $29 \%$ reduction from the baseline aircraft versus a goal of $33 \%$.

\section{Acknowledgements}

The authors would like to thank the Fixed Wing Project of NASA's Fundamental Aeronautics Program for supporting this study.

\section{References}

\footnotetext{
${ }^{1}$ Berton, J. J., Envia, E., Burley, C., “An Analytical Assessment of the NASA's N+1 Subsonic Fixed Wing Project Noise Goal," AIAA 2009-3144, May 2009.

${ }^{2}$ Guynn, M.D., Berton, J.J., Fisher, K.L., Haller, W.J., Tong, M., Thurman, D.R., "Engine Concept Study for an Advanced Single-Aisle Transport," NASA TM-2009-215784, August 2009.
} 
${ }^{3}$ Guynn, M.D., Berton, J.J., Fisher, K.L., Haller, W.J., Tong, M., Thurman, D.R., “Analysis of Turbofan Design Options for an Advanced Single-Aisle Transport Aircraft," AIAA 2009-6942, September 2009.

${ }^{4}$ Guynn, M.D., Berton, J.J., Fisher, K.L., Haller, W.J., Tong, M., Thurman, D.R., "Refined Exploration of Turbofan Design Options for an Advanced Single-Aisle Transport," NASA TM-2011-216883, January 2011.

${ }^{5}$ Hendricks, E.S., "Development of an Open Rotor Cycle Model in NPSS using a Multi-design Point Approach," GT201146694, ASME Turbo-Expo 2011, June 2011.

${ }^{6}$ Berton, J.J., Guynn, M.D., "Multi-Objective Optimization of Turbofan Design Parameters for an Advanced, Single-Aisle Transport," AIAA Journal of Aircraft, Vol. 48, No. 5, pp. 1795-1805, September-October, 2011.

${ }^{7}$ Guynn, M.D., Berton, J.J., Hendricks, E.S., Tong, M.T., Haller, W.J., "Initial Assessment of Open Rotor Propulsion Applied to an Advanced Single-Aisle Aircraft," AIAA 2011-7058, September 2011.

${ }^{8}$ Hendricks, E.S., Tong, M.T., "Performance and Weight Estimates for an Advanced Open Rotor Engine," AIAA-2012-3911, July 2012.

${ }^{9}$ Guynn, M.D., Berton, J.J., Haller, W.J., Hendricks, E.S., Tong, M.T., "Performance and Environmental Assessment of Advanced Aircraft with Open Rotor Propulsion," NASA TM-2012-217772, October 2012.

${ }^{10}$ Hendricks, E.S., Berton, J. J., Haller, W.J., Tong, M.T., Guynn, M.D., "Updated Assessment of an Open Rotor Airplane using Advanced Blade Designs," AIAA-2013-????, July 2013.

${ }^{11}$ Norris, G., "THE 737 STORY: Smoke and mirrors obscure 737 and Airbus A320 replacement studies," Flight International, 7 February 2006. URL: http://www.flightglobal.com/news/articles/the-737-story-smokeand-mirrors-obscure-737and-airbus-a320-replacement-204506/ [cited 7 June 2013].

${ }^{12}$ Claus, R.W.; Evans, A.L.; Lytle, J.K., and Nichols, L.D.: "Numerical Propulsion System Simulation," Computing Systems in Engineering, Vol. 2, No. 4, pp. 357-364, 1991.

${ }^{13}$ NPSS User Guide Software Release: NPSS 1.6.5.

${ }^{14}$ NPSS Reference Sheets Software Release: NPSS_1.6.5.

${ }^{15}$ Onat, E., and Klees, G., “A Method to Estimate Weight and Dimensions of Large and Small Gas Turbine Engines,” NASA CR 159481, 1979.

${ }^{16}$ Tong, M.T., Halliwell, I., and Ghosn, L.J., “A Computer Code for Gas Turbine Engine Weight and Life Estimation,” ASME Journal of Engineering for Gas Turbine and Power, Vol. 126, No. 2, pp. 265-270, April 2004.

${ }^{17}$ Tong, M.T., and Naylor, B.A., “An Object-Oriented Computer Code for Aircraft Engine Weight Estimation,” GT200850062, ASME Turbo-Expo 2008, June 2008.

${ }^{18}$ Albers, J.A., Felderman, E.J., "Boundary-Layer Analysis of Subsonic Inlet Diffuser Geometries for Engine Nacelles," NASA TN D-7520, March 1974.

${ }^{19}$ Miao, Z., "Aircraft Engine Performance and Integration in a Flying Wing Aircraft Conceptual Design," MSc Thesis, Cranfield University, January 2012.

${ }^{20}$ Stewart, W.: "Analytical Investigation of Multistage-Turbine Efficiency Characteristics in Terms of Work and Speed Requirements," NACA RM E57K22b, 1958 (unclassified 1970).

${ }^{21}$ Tong, M.T., Jones, S.M., Haller, W.J., Handschuh, R.F., "Engine Conceptual Design Studies for A Hybrid Wing Body Aircraft,"NASA TM-2009-215680, November 2009.

${ }^{22}$ Guynn, M.D., "First-Order Altitude Effects on the Cruise Efficiency of Subsonic Transport Aircraft," NASA TM-2011217173, August 2011.

${ }^{23}$ McCullers, L., “Aircraft Configuration Optimization Including Optimized Flight Profiles,” Proceedings of the Symposium on Recent Experiences in Multidisciplinary Analysis and Optimization, NASA CP 2327, April 1984.

${ }^{24}$ Gillian, R.E., “Aircraft Noise Prediction Program User's Manual,” NASA TM-84486, 1983.

${ }^{25}$ Burley, C., and Rawls, J., "Aircraft Noise Prediction Program (ANOPP) Theoretical Manual," Currently maintained at NASA Langley by the ANOPP team in electronic format and provided upon request; Latest revision: Level 30v3, January 2013.

${ }^{26}$ U.S. Code of Federal Regulations, Title 14, Chap. I, Part 36, Noise Standards: Aircraft Type and Airworthiness Certification, January, 2012.

${ }^{27}$ Kontos, K.B., Janardan, B., and Gliebe, P.R., "Improved NASA-ANOPP Noise Prediction Computer Code for Advanced Subsonic Propulsion Systems Volume 1: ANOPP Evaluation and Fan Noise Model Improvement," NASA CR-195480, 1996.

${ }^{28}$ Heidmann, M.F.: "Interim Prediction Method for Fan and Compressor Source Noise," NASA TMX-71763, 1979.

${ }^{29}$ Dittmar, J.H., Elliott, D.M., and Bock, L.A., "Some Acoustic Results from the Pratt and Whitney Advanced Ducted Propulsor - Fan 1,”NASA TM-1999-209049, 1999.

${ }^{30}$ Neubert, R., Bock, L., Malmborg, E., and Owen-Peer, W., “Advanced Low Noise Research Fan Stage Design,” NASA CR 97-206308, 1997.

${ }^{31}$ Kontos, K.B., Kraft, R.E., and Gliebe, P.R., "Improved NASA-ANOPP Noise Prediction Computer Code for Advanced Subsonic Propulsion Systems. Volume 2: Fan Suppression Model Development,” NASA CR-202309, 1996.

${ }^{32}$ Michel, U., "Correlation of Aircraft Certification Noise Levels EPNL with Controlling Physical Parameters," $19^{\text {th }}$ AIAA/CEAS Aeroacoustics Conference, Berlin, Germany, AIAA-2013-2014, May, 2012.

${ }^{33}$ Chien, C.F., and Soroka, W.W., "Sound Propagation Along an Impedance Plane," J. Sound and Vibration, Vol. 43, No. 1, 8 Nov. 8 1975, pp. 9-20. 
${ }^{34}$ International Civil Aviation Organization (ICAO), Committee on Aviation Environmental Protection: "Environmental Technical Manual, Volume I, Procedures for the Noise Certification of Aircraft,” Based on Doc. 9501, Vol. I, 1 st ed., July 2012.

${ }^{35}$ Embleton, T.F.W., Piercy, J.E., and Daigle, G.A., "Effective Flow Resistivity of Ground Surfaces Determined by Acoustical Measurements," J. Acoustical Society of America, Vol. 74, No. 4, 1983, pp. 1239-1244.

${ }^{36}$ Society of Automotive Engineers Committee A-21, "Method for Predicting Lateral Attenuation of Airplane Noise," Aerospace Information Report 5662, April, 2006.

${ }^{37}$ Fink, M.R., “Airframe Noise Prediction Method,” FAA-RD-77-29, March, 1977.

${ }^{38}$ Norris, G., “Actual Mileage May Vary,” Aviation Week and Space Technology, Vol. 174, No. 12, 2 April 2012, p. 28.

${ }^{39}$ U.S. Code of Federal Regulations, Title 14, Chapter I, Part 34. Fuel Venting and Exhaust Emission Requirements for Turbine Engine Powered Airplanes, January, 2012. 